\title{
Tuberculosis of Sacrum
}

\author{
Viroj Wiwanitkit \\ Faculty of Medicine, University of Nis, Nis, Serbia
}

Dear Editor,

The recent report by Sament et al. [1] on tuberculosis of sacrum is very interesting. We here present a case with monoparesis. The case of tuberculosis of sacrum is uncommon and can be delay-diagnosed. Kumar et al. [2] noted that this disorder has to be included in differential diagnosis of patients presenting with sacral mass lesion in tropical countries. The condition can present severe low back pain, and may have radiating pain and neurological alteration in lower extremities [3]. The management of the condition is usually by antituberculotic drug and surgical decompression [3]. The difficulties are often in the diagnostic phase. Since the radiological manifestation of tuberculosis diskitis/osteomyelitis is often similar to pyogenic diskitis/osteomyelitis, although it can be differentiated from malignancy, it is extremely difficult to make a clear diagnosis [4]. The open biopsy can be useful, which may be done for decompression to relieve patient's clinical symptoms. The present case has the interesting concern of monoparesis. Spinal stenosis due to spinal tuberculosis can present this clinical feature. The compression of the cord can be in any direction, and it may be more probable in cases of sacral lesion, since the sacral spine has a wider area compared to other parts of the spine.

\section{Conflict of Interest}

No potential conflict of interest relevant to this article was reported.

\section{References}

1. Sament R, Bachhal V, Gopinathan NR, Sen RK. Isolated tuberculosis of sacrum with monoparesis: an atypical presentation. Asian Spine J 2013;7:351-4.

2. Kumar A, Varshney MK, Trikha V. Unusual presentation of isolated sacral tuberculosis. Joint Bone Spine 2006;73:751-2.

3. Wellons JC, Zomorodi AR, Villaviciencio AT, Woods CW, Lawson WT, Eastwood JD. Sacral tuberculosis: a case report and review of the literature. Surg Neurol 2004;61:136-9.

4. Coffman GJ. Presentation of a rare sacral tuberculosis in an otherwise healthy patient: diagnostic challenge and review of treatment. J La State Med Soc 2012;164:67-9.

Received Jan 2, 2014: Revised Jan 2, 2014; Accepted Jan 2, 2014 